Vol. 3, Issue 1, December 2020

\title{
A Summary of Effective Gender Equitable Teaching Practices in Informal STEM Education Spaces
}

\author{
Roxanne Hughes, Ph.D.'; Jennifer Schellinger, Ph.D.'; Barbara Billington, Ph.D.'; Brenda Britsch, Ph.D.3; and Alicia \\ Santiago, Ph.D. ${ }^{4}$ \\ ${ }^{1}$ Florida State University, Tallahassee, FL; ${ }^{2}$ University of Minnesota, Minneapolis, MN; ${ }^{3}$ National Girls Collaborative Project, Seattle, WA; and ${ }^{4}$ SciGirls, Minneapolis, \\ MN
}

Keywords: Girls, Girls of Color, Gender Equity, Informal STEM Education

Publication Date: December 21, 2020

DOI: https://doi.org/10.15695/jstem/v3i1.16

\begin{abstract}
Women and girls, particularly women and girls of color, remain underrepresented in STEM disciplines. This underrepresentation begins as early as late elementary school age. Educators, particularly those in informal STEM education, can help address gender inequity in STEM by understanding how research can be translated into actionable strategies. This article summarizes research on gender equitable practices for middle school girls in the last decade and addresses the disconnect between research and practice by presenting the findings in a way that educators can immediately act on. The research falls into six strategies that have demonstrated positive influences on gender inequity in STEM education: (1) connecting STEM experiences to girls' lives; (2) supporting girls as they investigate questions and solve problems using STEM practices; (3) empowering girls to embrace struggle, overcome challenges, and increase self-confidence in STEM; (4) encouraging girls to identify and challenge STEM stereotypes; (5) emphasizing that STEM is collaborative, social, and community-oriented; (6) providing opportunities for girls to interact with and learn from diverse STEM role models. Our review highlights that each of these strategies are important to developing positive STEM identities in girls, particularly girls of color, which can help them to bridge the STEM gender and racial gap.
\end{abstract}

\section{INTRODUCTION}

Women remain underrepresented in many of the science, technology, engineering, and math (STEM) fields compared to their representation in the US population (National Science Foundation (NSF), 2019). Women hold less than 30\% of STEM jobs, with Latina/Hispanic, African American/ Black, and Indigenous women representing less than $10 \%$ of these jobs (NSF, 2019). Research points to late elementary school and early middle school as the developmental stage wherein gender differences begin to occur in girls' perceived sense of belonging and potential future success in STEM careers because of historical examples and cultural stereotypes that portray STEM as white and male (Calabrese Barton et al., 2013; Kim et al., 2018; Tan et al., 2013). Research has highlighted the benefits of informal STEM education programs as venues that can strengthen girls' interest and sense of belonging in STEM at this age (Adams et al., 2014; Cakir et al., 2017; National Research Council, 2009; Riedinger and Taylor, 2016; Sammet and Kekelis, 2018). As part of the authors' efforts to advocate best practices for gender equita- ble informal STEM education at this developmental level, we have compiled this literature review which focuses on strategies that have shown positive results in improving and/ or sustaining girls' interest in STEM and sense of belonging in STEM careers in the last decade.

STEM Identity. The concept of STEM identity was the lens through which we searched the literature and developed our review of gender equitable strategies. We chose the foundational definition of the construct from Calabrese Barton et al. (2013), Eccles (2007), and Carlone and Johnson (2007). According to these researchers, STEM identity requires opportunities to develop interest and competence in STEM-related skills, perform these competencies, and be recognized by perceived experts (Carlone and Johnson, 2007). Youth must experience a sense of competence and opportunity for potential success in their chosen field and see value in these fields (Eccles, 2007). STEM identity development is both a reflection of how one perceives, positions, and aligns one- 
self with STEM, and how one is perceived and recognized by meaningful others (Calabrese Barton et al., 2013). STEM identity development is both individual and contextual. It is impacted by girls' - and the peers and adults in their lives' - stereotypes related to gender, race, and STEM disciplines that are informed and shaped by power differentials and social constructs (Collins and Bilge, 2016). Girls of color must overcome the inherent racist and sexist stereotypes to develop a strong STEM identity to feel like they belong even when they are marginalized and isolated within the field. Educators play an important role in helping (or hurting) girls, particularly girls of color, to see themselves as STEM people due to the educators' stereotypes (Hughes et al., 2020).

Middle School as a Turning Point in STEM Identity. Middle school is a crucial time to sustain and improve girls' STEM identities. It is during the middle school years when girls are deciding what kind of girl to be and figuring out desired versions of their future selves (Allen and Eisenhart, 2017; Carlone et al., 2015). Girls author their identities. This authoring is shaped by how they see themselves and how others see them in multiple spaces (e.g. in-school, out-ofschool, home/family (Allen \& Eisenhart, 2017; Calabrese Barton et al., 2013; Koch et al., 2015)) and across intersecting power domains related to gender, race, ethnicity, and class (Archer et al., 2015; Brunning et al., 2015; Carlone et al., 2015; Thomas et al., 2017).

Research highlights that girls at the middle school age may not be able to differentiate between the various disciplines of science or how technology differs from engineering and mathematics (CAISE, 2018). Therefore, we have chosen to use the term STEM identity throughout this paper. The articles we cite will focus on a range of STEM disciplines. In each discussion we will use the author(s)' term and definition if applicable. Not all of the articles provide a definition of identity (e.g. Riedinger and Taylor, 2016), so we used our framing definition to help us define search terms. A consistent definition or understanding of STEM identity is missing from the STEM education literature. However, our framework allowed us to include a variety of studies that focused on aspects of identity.

Informal STEM Education Spaces. Although we focused on articles of formal and informal STEM education (ISE), it is important to highlight the value of ISE spaces as they are often overlooked in education policy discussions compared to formal education, which is unfortunate considering K-12 aged students spend the majority ( $81 \%$ ) of their time in nonschool settings (National Research Council (NRC), 2009). Informal education has been cited as beneficial to STEM learning because it allows learners to engage with concepts in environments that provide them time and space to cognitively struggle with ideas that they find personally meaning- ful. STEM focused afterschool and summer programs can give learners time to practice and reflect on STEM skills, such as asking questions, communicating ideas, and drawing conclusions. In addition, ISE programs can improve equity issues inherent in STEM fields by connecting STEM practices from the various ecosystems of youth's lives (family, school, out-of-school, and community) (Barron and Bell, 2015; Philip and Azevedo, 2017).

\section{METHODS}

The purpose of this review was to examine and synthesize recent literature grounded in research in gender equity in STEM to identify key factors that influence the development of girls' positive STEM identities as well as effective instructional strategies for building girls' identity in STEM fields. This work builds on the literature review created in 2013 as part of the SciGirls Seven Strategies (SG7). The foundational literature review was created in 2009 and up-

Table 1. SciGirl Seven Strategies.

Strategy 1 Girls benefit from collaboration, especially when they can participate and communicate fairly. Girls thrive when they work together to make science, technology and engineering an intentionally social experience.

Strategy 2 Girls are motivated by projects they find personally relevant and meaningful. Girls become motivated when they feel they can make a difference. If girls see STEM as relevant to their own lives, their attraction to these subjects is likely to increase.

Strategy 3 Girls enjoy hands-on, open-ended projects and investigations. Educators and role models can encourage and promote exploration, imagination, and invention by encouraging girls to ask questions and find their own paths for investigation.

Strategy 4 Girls are motivated when they can approach projects in their own way, applying their creativity, unique talents, and preferred learning styles. Girls should take ownership of their own investigations, collecting data, solving problems and communicating their findings and results.

Strategy 5 Girls' confidence and performance improves in response to specific, positive feedback on things they can control-such as effort, strategies, and behaviors. Self-confidence can make or break girls' interest in STEM. Adults can support girls' efforts by encouraging their problem-solving strategies; allowing them to struggle and/or fail; emphasizing that their skills can be improved through practice.

Strategy 6 Girls gain confidence and trust in their own reasoning when encouraged to think critically. Educators should cultivate an environment that encourages creative thinking, questioning, trial and error and authentic, personal discoveries.

Strategy 7 Girls benefit from relationships with role models and mentors. Seeing women who have succeeded in STEM helps inspire and motivate girls. By hosting field trips and visiting programs, role models tangibly demonstrate how girls can succeed. 
dated in 2013 as a set of seven research-based strategies (Table 1) (Billington et al., 2014).

Since this initial literature review in 2009 and update in 2013, researchers, policymakers and practitioners have focused research and resources on issues affecting girls' lowered interest and persistence in STEM (e.g. Corbett and Hill, 2015; McCreedy and Dierking, 2013). In addition, researchers have highlighted how stereotypes intersect across marginalized identities that prevent girls of color from becoming interested and/or persisting in STEM (e.g. Collins and Bilge, 2016; Jones, 2019). Therefore, we felt a need to update the literature to account for the fact that not all girls have the same experience in STEM. Hence, our focusing question for this literature review was: What are current gender equitable strategies that can help girls of diverse backgrounds and identities see themselves as STEM people?

For this literature review, we searched for terms associated with the original SG7 and our conceptual framework via Google Scholar and ERIC. These terms included: STEM identity. interest, engagement, motivations, attitudes, self-efficacy, STEM capital, and perceptions of and attitudes toward STEM careers and STEM. We also searched the literature for research focused on girls of color. This resulted in 45 peer-reviewed articles focused on K-16 formal and informal settings from 2013-2018. At least one of the authors read each article from one or more of the seven original strategies and wrote summaries about each article. The authors came together monthly to discuss and negotiate their findings. A matrix was created in excel based on the findings for each of the categories by the SG7, and additional categories were added based on emergent themes from the literature examined.

\section{FINDINGS}

Some of the original strategies were combined and new strategies emerged based on our review. We identified six themes that we present as the six SciGirls strategies that support girls in their development of positive STEM identities:

- connecting STEM experiences to girls' lives;

- supporting girls as they investigate questions and solve problems using STEM practices;

- empowering girls to embrace struggle, overcome challenges, and increase self-confidence in STEM;

- encouraging girls to identify and challenge STEM stereotypes;

- emphasizing that STEM is collaborative, social, and community-oriented;

- providing opportunities for girls to interact with and learn from diverse STEM role models.
We provide details for each article cited in Appendix A, including: authors, methods, sample size and demographics, age range, SciGirls strategies supported, STEM discipline discussed, formal or informal education, and length of intervention. The order below does not represent a hierarchical ordering but rather a convention for organization and reference. Some articles spoke to multiple strategies.

1. Connect STEM Experiences to Girls' Lives. Women, Black/African Americans, Indigenous people, and Latina/o/x and Hispanic Americans have historically been marginalized by STEM fields due to a lack of cultural relevance and connections to non-dominant groups' everyday lives (McCreedy and Dierking, 2013). If youth do not see their own culture reflected in STEM, then they will not see themselves as potentially succeeding in STEM. Therefore, the first SciGirls strategy is to connect STEM experiences to girls' lives. Personal relevance (e.g. allowing participants to focus on local problems or issues affecting their community) brings marginalized students' interest and knowledge to the forefront of the discussion (Buck et al., 2014; McCreedy and Dierking, 2013; Polman and Hope, 2014; Riedinger and Taylor, 2016). Research has demonstrated the value that culturally relevant teaching can add to youth's sense of belonging in STEM because it empowers girls, especially girls of color, by incorporating not just their interests but also their identities, cultures, backgrounds and experiences, by making them central to the learning process (Hubert, 2014). Research highlights that youth see all STEM disciplines as inherently white and middle class and certain STEM disciplines as more masculine (e.g. physics) and others as more feminine (e.g. biology) (Archer et al., 2013; Archer et al., 2017; Gonsalves, 2013). This perception begins at the middle school age and continues throughout secondary school leading girls to feel less of a connection to those disciplines deemed masculine, and girls of color to feel less of a connection to all STEM fields. Programs that allow girls to drive the design around personally relevant topics (e.g. creating experiences for girls to explore topics that they care about or that impact their community) improve their interest and attitudes toward science and technology (Buchholz et al., 2014; Cakir et al., 2017; Erete et al., 2016; Robinson et al., 2016; Stewart-Gardiner et al., 2013; Thomas et al., 2017). For example, educators can ask girls about their backgrounds, interests, and community to connect STEM to their lives or they can have girls choose topics to explore that they find personally relevant and meaningful.

\section{Support Girls as They Investigate Questions and} Solve Problems Using STEM Practices. STEM practices are authentic behaviors that align with the ways of doing science used by STEM professionals (NGSS Lead States, 2013). When girls take ownership of their own STEM learning and engage in meaningful STEM work, it positively in- 
fluences their perceptions of STEM fields, their identities, and re-defines what STEM is (Buchholz et al., 2014; Kim, 2016; Scott and White, 2013; Riedinger and Taylor, 2016). The authentic activities in these studies included: doing the work of scientists (e.g., collecting field ecology specimens or designing a LEGO project), using the tools (e.g., refractometers) of STEM professionals (Buchholz et al., 2014; Riedinger and Taylor, 2016) and addressing open ended questions without a correct answer (Kim, 2016). By introducing girls to various STEM practices (e.g. designing and problem solving) with materials (e.g., e-textiles) and in environments where they felt supported in their attempts at new practices and terms, they were more confident to engage in STEM practices resulting in more positive STEM identity development. For example, educators can create STEM opportunities that are open-ended and allow girls to use everyday language to make sense of STEM terminology.

\section{Empower Girls to Embrace Struggle, Overcome Chal- lenges and Increase Self-Confidence. Girls' confidence} and performance improves when they are given specific, positive feedback on things that challenge them but are within their control to overcome-such as the strategies they employ, the behaviors they exhibit and the processes they engage in (Degol et al., 2018; Ryoo and Kekelis, 2018; Simpson and Maltese, 2017). To benefit from this feedback, individuals need to hold a growth mindset wherein they believe that they can strengthen their abilities through practice and application (Dweck, 2006; Dweck et al., 2014). Grappling with problems in STEM has been described as uncertainty or struggle. To be productive, these moments of uncertainty need to be framed as opportunities to learn, not as mistakes or failures. When mistakes or failures are viewed as unwanted results, they can be associated with a lack of achievement and can negatively influence a girl's sense of belonging and potential for success in STEM disciplines (Simpson and Maltese, 2017). However, when struggle is framed as part of the learning process and opportunities for this struggle are provided, girls' come to develop expertise and confidence in their abilities (Warshauer, 2015).

Informal educational settings are uniquely situated to support this culture because of the additional resources and time for engagement in and reflection of ill-defined problems or activities (Jethwani et al., 2016; Ryoo and Kekelis, 2018; Thomas et al., 2017). However, much of the research related to productive struggle has occurred in formal classroom settings in the context of mathematics and science (Toh and Kapur, 2017; Warshauer, 2015). This research points to the positive impact that certain types of cognitive dissonance have on learners' understanding of science and mathematics (Simpson and Maltese, 2017; Toh and Kapur, 2017). Formal classroom settings do not always support a culture of mistakes and errors (Carlone, 2003; Dweck, 2006) due to pressures to prepare students to understand a breadth of con-

tent and to excel at standardized tests which measure their understanding of this content (Anderson, 2012). Educators play a pivotal role in supporting girls to struggle productively and to understand that they are capable of overcoming and excelling through such challenges. For example, educators can reiterate that working through problems and having experiments fail is a normal part of the STEM process and leads to learning. To support girls through frustration, educators can ask questions that get at the process (e.g. how did you determine that answer, what other steps could you take) and praise girls for utilizing strategies and behavior (e.g. persistence, challenge seeking) that they can control.

\section{Encourage Girls to Identify and Challenge STEM Ste-} reotypes. STEM stereotypes fall into two categories: (1) Stereotypes related to perceptions (and in some cases reality) of STEM fields as lonely, white, masculine and unfriendly to women and people of color, which in turn affects individuals' sense of belonging (Archer et al., 2017; Hughes, 2015; Bricker and Bell, 2014; Buchholz et al., 2014; Carlone et al., 2015; Hillman et al., 2014; Lock and Hazari, 2016; Master et al., 2016; O'Brien et al., 2016; Scott and White, 2013); and (2) Stereotypes associated with traditional school science which privileges the idea that science is based on known facts and results are based on a rigid scientific method leaving minimal room for curiosity or mistakes (Calabrese Barton et al., 2013; Carlone et al., 2014). Teachers and parents play a crucial role in reinforcing the masculine stereotype associated with STEM fields that continues to prevent "girly girls" from seeing opportunities for success in STEM or seeing themselves as belonging (Archer et al., 2015; Archer et al., 2013; Buchholz et al., 2014; Carlone et al., 2015; Calabrese Barton et al., 2013; Lock and Hazari, 2016; Master et al., 2016).

Girls with multiple marginalized identities must negotiate multiple power dynamics and stereotypes to identify with STEM. Studies that focused on girls of color highlight the complexity of STEM identity development for youth (Archer et al., 2015; Bruning et al., 2015; Erete et al., 2016; Richard, 2016; Scott and White, 2013). School science has additional stereotypes associated with the concept of being a good science student, particularly for girls of color (Carlone et al., 2015; Carlone et al., 2014; Tan et al., 2013). Studies have shown that girls are often forced to conform to behaviors such as quiet note-takers which prevents them from gaining skills in STEM such as tinkering, taking risks, and arguing their findings. Girls who do exhibit these STEM skills are often penalized or punished for it (Carlone et al., 2015; Carlone et al., 2014; Tan et al., 2013).

In terms of gender, stereotypes related to intelligence begin as early as age five when gendered views emerge in which boys are viewed as smarter than girls by both sexes (Bian et al., 2017). This stereotype only increases among youth as 
they grow older and stereotypes are reinforced by parents, peers and educators (Hazari et al., 2015; Riegle-Crumb and Morton, 2017; Tan et al., 2013). In addition, our culture recognizes certain fields as being legitimate STEM disciplines (e.g. physics, chemistry, biology). However, fields that utilize STEM, which have historically been dominated by women such as food science or home economics, have been labeled less scientific (McCreedy and Dierking, 2013). Challenging these various stereotypes helps girls to develop a stronger STEM identity that can withstand setbacks in their STEM trajectories (Lock and Hazari, 2016). Educators can position girls to challenge stereotypes by providing diverse examples of STEM professionals either through in-person or virtual role model interactions as well as highlighting media and images that show diverse role models.

\section{Emphasize that STEM is Collaborative, Social and} Community-Oriented. Beyond the stereotype related to the masculinity of STEM fields, research shows that youth hold stereotypical views of STEM as lonely fields that do not allow practitioners to help others (Carli, et al., 2016). This stereotype often prevents girls who see altruism as central to their gender identity, from seeing these fields as congruent with their communal goals of working with and helping others (Diekman et al., 2015). Collaboration is essential to STEM. STEM discoveries happen via collaboration and the communication of STEM is inherently social and community-oriented. Research provides evidence of the benefits of creating programs that include collaboration and community responsiveness as beneficial to girls' sense of belonging to STEM (Adams et al., 2014; Buck et al., 2014; Cantley et al., 2017; Riedinger and Taylor, 2016). Working with others in an inclusive, collegially nurturing space increases girls' confidence about their ability, allows them to exchange ideas and consider and explore their own and diverse perspectives (Riegle-Crumb and Morton, 2017). This offers opportunities to build relationships and a collective identity that ultimately strengthens girls' STEM identity (Ryoo and Kekelis, 2018). Educators can provide multiple opportunities for girls to interact, work together, and get to know each other so that they feel comfortable sharing and negotiating their ideas. Educators and STEM role models can share examples of how STEM fields provide opportunities to work together, help others and give back to the community.

\section{Provide Opportunities for Girls to Interact With and Learn From Diverse Women STEM Role Models. Engag-} ing girls, particularly girls of color, with role models is a successful strategy for countering stereotypes related to who succeeds and belongs in STEM (Weisgram and Diekman, 2017). In particular, girls need to meet role models with diverse backgrounds from multiple STEM fields to break down stereotypes and develop STEM identities (Adams et al., 2014; Hughes, 2015; Hughes and Molyneaux, 2014; Je- thwani et al., 2016; Koch et al., 2015; Levine et al., 2015; O'Brien et al., 2016). When girls can relate to role models as multidimensional people with diverse lived experiences, they develop a broader mental picture of what it looks like to be a STEM person and expand their vision of what is professionally and personally possible in their own lives (Hillman et al., 2014; Weisgram and Diekman, 2017). While short one-time exposures to role models are beneficial, they may not be enough to maintain a young woman's interest in STEM longitudinally (Hughes, 2015). Girls must be given varied opportunities (e.g. in person and through stories/ videos) repeatedly over time. Youth need to have agency in choosing and reflecting on role models for role model interventions to be successful (Lock and Hazari, 2016; O'Brien et al., 2016). The type of role model exposure is important - role model interventions that address discrimination and sexism prepare young women for the issues they will face as they progress in their education and in the workplace and help them to be more resilient (Lock and Hazari, 2016). Educators must work actively to include role models who are supportive, engaging, relatable and who mirror the diversity of the girls. Educators can coach role models to conduct hands-on, inquiry activities with the girls, to be honest about their experiences in STEM, and to discuss their rich lives outside of STEM.

\section{DISCUSSION}

How STEM Identity Development is Best Supported. The six themes discussed in this literature are not siloed, rather they can intersect and overlap to strengthen girls' STEM identity. Educators play a crucial role in facilitating these six strategies. If girls do not see how STEM relates to their lives, see themselves as competent in STEM, have opportunities to demonstrate and be recognized for these competencies or see themselves as able to succeed in STEM, then they will not persist in or pursue STEM. Therefore, for programs and instructional techniques to be successful they must in some way address the components of identity that we have listed. All six strategies require girls to have confidence to share their experiences, pursue challenging problems, and ask questions of others. This cannot be done if girls do not feel valued or safe in the environment.

In the last decade, the call for safe and inclusive environments where girls feel like they belong has been raised (Hubert, 2014; Sammet and Kekelis, 2016). And yet, many research studies have not focused on the learning environment (for some exceptions see: Adams et al., 2014; Cakir et al., 2017; Riedinger and Taylor, 2016; Thomas et al., 2017). But to fully support girls from diverse backgrounds, including girls of color in STEM, we need to move beyond inclusion and incorporate culturally responsive teaching (Brown, 2017; Gay, 2013; Ladson-Billings, 2008; 2014). Future stud- 


\section{Framework}

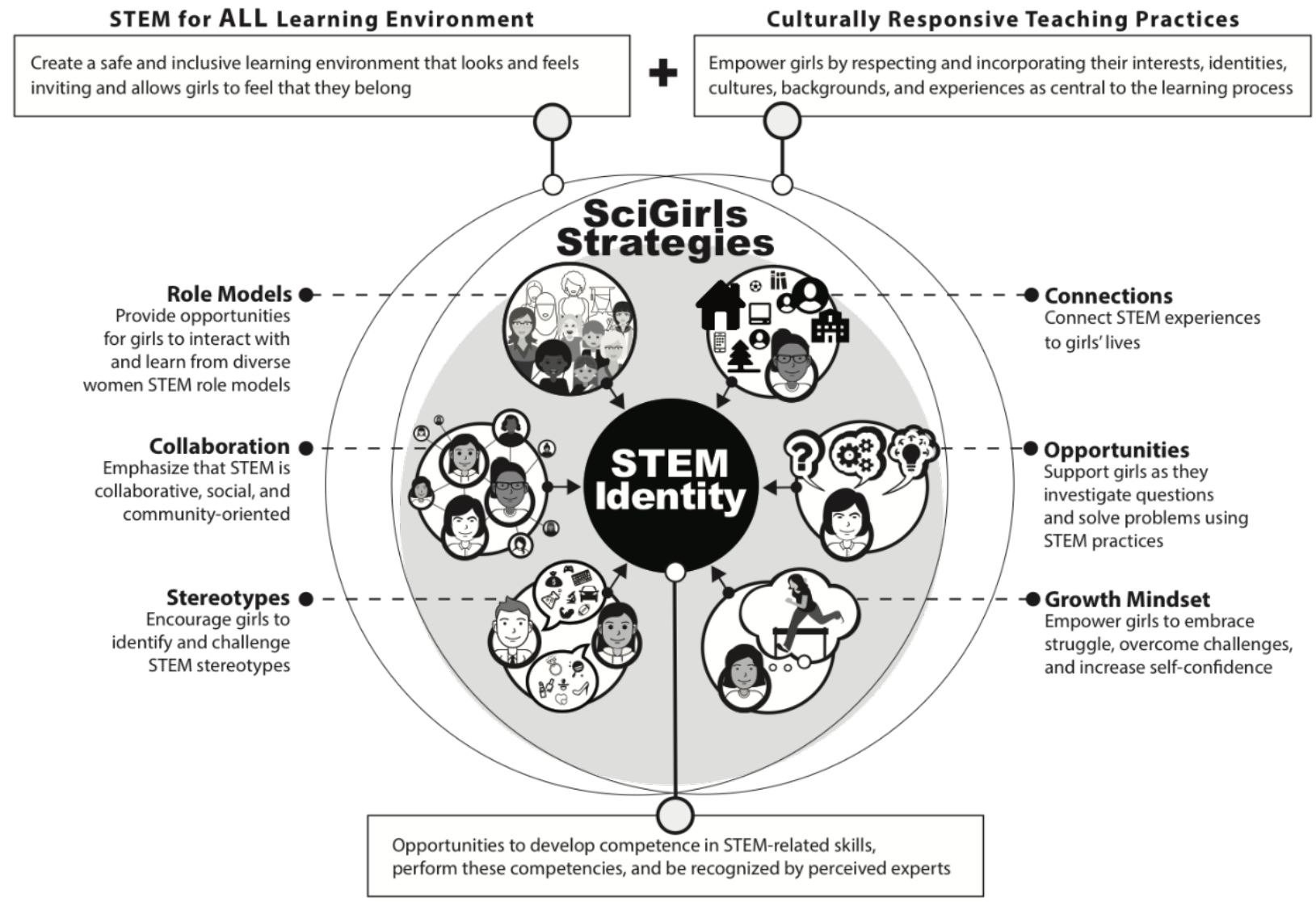

Figure 1. Gender-equitable framework to support STEM identity development including the six themes and overarching constructs.

ies and reviews should focus on the space created, not just on what happens within the space. For example, culturally responsive teaching is more than just connecting STEM to students' lives, it is making their lives central and valuable to the understanding of STEM (Brown, 2017; Brown et al., 2018). And yet there is limited research on the impact of culturally responsive teaching in formal and informal STEM education environments (Brown, 2017; Civil, 2016; Scott et al., 2014). We advocate for researchers to look at how these six strategies can be amplified if they occur within an inclusive and culturally responsive informal STEM education space where girls' interests drive the questions asked and the activities conducted. This focus on girls driving STEM is a cultural shift for both STEM education and STEM disciplines. STEM cannot become more inclusive until we all act toward and demand cultural change that empowers those voices who have been silenced.

Conclusion. This literature review highlights the call for an intersectional identity lens for studying and improving girls', particularly girls of color, opportunities to thrive not just survive in STEM. If women and girls, especially those from underserved populations, are to be equally represented in STEM fields, they must be provided with opportunities to develop strong STEM identities that bridge the STEM gender gap that puts the stereotype of being "girly" at odds with being "scientific" (Carlone et al., 2015). They must have opportunities to see and develop strategies to counter how racism and sexism can intersect to push women and girls out. The literature review conducted here has updated gender equitable instructional strategies to inform educators' decisions and support girls to develop and sustain their STEM identities. We advocate for researchers to look at how these six strategies can be amplified if they occur within an inclusive and culturally responsive informal STEM education space where girls' interests drive the questions asked and the activities conducted: An example of the framework that includes all of these pieces can be found in Figure 1. We also propose a research-based theoretical framework for future researchers to test the benefits of these strategies and how the foundational pieces influence girls' STEM identities.

\section{ASSOCIATED CONTENT}

Supplemental material mentioned in this manuscript can be found uploaded to the same webpage as this manuscript. 


\section{AUTHOR INFORMATION \\ Corresponding Author}

Roxanne Hughes, Ph.D. Florida State University.

hughes@magnet.fsu.edu

\section{Author Contributions}

The manuscript was written through contributions of all authors. All authors have given approval to the final version of the manuscript.

\section{FUNDING SOURCES}

This work was supported by the National Science Foundation Division of Research on Learning grant: DRL1612605. A portion of this work was performed at the National High Magnetic Field Laboratory, which is supported by the National Science Foundation Cooperative Agreement No. DMR-1644779 and the state of Florida.

\section{ABBREVIATIONS}

ISE: Informal STEM Education; NRC: National Research Council; NSF: National Science Foundation; SG7: SciGirls Seven Strategies; STEM: Science, Technology, Engineering, and Math;

\section{REFERENCES}

Adams, J. D., Gupta, P., and Cotumaccio, A. (2014). Long-term participants: A museum program enhances girls' STEM interest, motivation, and persistence. Afterschool Matters, 20, 13-20.

Allen, C. D., and Eisenhart, M. (2017). Fighting for desired versions of a future self: How young women negotiated STEM-related identities in the discursive landscape of educational opportunity. Journal of the Learning Sciences, 26(3), 407-436.

Anderson, K. J. B. (2012). Science education and test-based accountability: Reviewing the relationship and exploring implications for future policy. Science Education, 96, 104129.

Archer, L., Dawson, E., DeWitt, J., Seakins, A., and Wong, B. (2015). "Science Capital": A conceptual, methodological, and empirical argument for extending Bourdieusian notions of capital beyond the arts. Journal of Research in Science Teaching, 52, 922-948.

Archer, L., DeWitt, J., Osborne, J., Dillon, J., Willis, B., and Wong, B. (2013). 'Not girly, not sexy, not glamorous': Primary school girls' and parents' constructions of science aspirations. Pedagogy, Culture and Society, 21(1), 171-194.
Archer, L., Moote, J., Francis, B., DeWitt, J., and Yeomans, L. (2017) The "exceptional" physics girl: A sociological analysis of multimethod data from young women aged 1016 to explore gendered patterns of post-16 participation. American Educational Research Journal, 54(1), 88-126.

Barron, B., and Bell, P. (2015). Chapter 24: Learning environments. In and out of school. Handbook of Educational Psychology (3rd Edition), p 323-336.

Bian, L., Leslie, S. J., and Cimpian, A. (2017). Gender stereotypes about intellectual ability emerge early and influence children's interests. Science, 355(6323), 389-391.

Billington, B., Britsch, B., Karl, R., Carter, S., Freese, J., and Regalla, L. (2014). SciGirls Seven: How to engage girls in STEM. Minneapolis, MN: Twin Cities Public Television. http://tpt.vo.llnwd.net/o26/scigirls/ScigirlsSeven_Print. pdf

Bricker, L. A., and Bell, P. (2014). "What comes to mind when you think of science? The perfumery!": Documenting science-related cultural learning pathways across contexts and timescales. Journal of Research in Science Teaching, 51(3), 260-285.

Brown, J.C. (2017). A metasynthesis of the complementarity of culturally responsive and inquiry-based science education in K-12 settings: implications for advancing equitable science teaching and learning. Journal of Research in Science Teaching, 54(9), 1143-1173.

Brown, BA., Boda, P., Lemmi, C., and Monroe, X. (2018). Moving culturally relevant pedagogy from theory to practice: Exploring teachers' application of culturally relevant education in science and mathematics. Urban Education, 54(6), 775-803. DOI: $10.1177 / 0042085918794802$

Bruning, M. J., Bystydzienski, J., and Eisenhart, M. (2015). Intersectionality as a framework for understanding diverse young women's commitment to engineering. Journal of Women and Minorities in Science and Engineering, 21(1), $1-26$.

Buchholz, B., Shively, K., Peppler, K., and Wohlwend, K. (2014). Hands on, hands off: Gendered access in crafting and electronics practices. Mind, Culture, and Activity, 21(4), 278297.

Buck, G. A., Cook, K. L., Quigley, C. F., Prince, P., and Lucas, Y. (2014). Seeking to improve African American girls' attitudes toward science: A participatory action research project. The Elementary School Journal, 114(3), 431-453.

Çakır, N. A., Gass, A., Foster, A., and Lee, F. J. (2017). Development of a game-design workshop to promote young girls' interest towards computing through identity exploration. Computers and Education, 108, 115-130.

Calabrese Barton, A., Kang, H., Tan, E., O'Neill, T. B., Bautista-Guerra, J., and Brecklin, C.(2013). Crafting a future in science: Tracing middle school girls' identity work over time and space. American Educational Research Journal, 50(1), 37-75. 
Cantley, I., Prendergast, M., and Schlindwein, F. (2017). Collaborative cognitive-activation strategies as an emancipatory force in promoting girls' interest in and enjoyment of mathematics: A cross-national case study. International Journal of Educational Research, 81, 38-51.

Carli, L.L, Alawa, L., Lee, Y., Zhao, B., and Kim, E. (2016). Stereotypes about gender and science: Women $\neq$ scientists. Psychology of Women Quarterly, 40(22), 244-260.

Carlone, H.B., and Johnson, A. (2007). Understanding the science experiences of successful women of color: Science identity as an analytic lens. Journal of Research in Science Teaching, 44(8), 1187-1218.

Carlone, H. B., Johnson, A., and Scott, C. M. (2015). Agency amidst formidable structures:How girls perform gender in science class. Journal of Research in Science Teaching, 52(4), 474-488.

Carlone, H. B., Scott, C. M., and Lowder, C., (2014), Becoming (less) scientific: A longitudinal study of students' identity work from elementary to middle school science. Journal of Research in Science Teaching, 51(7), 836-869.

CAISE (2018). What is STEM Identity? Retrieved on October 1, 2018 from http://informalscience.org/identity

Civil, M. (2016). STEM learning research through a funds of knowledge lens. Cultural Studies of Science Education, 11(1), 41-59.

Collins, P.H., and Bilge, S. (2016). Intersectionality. Malden, MA: Polity Press.

Corbett, C., and Hill, C.H. (2015). Solving the equation: The variables for women's success in engineering and computing., American Association of University Women, Washington, DC: 2015.

Degol, J. L., Wang, M. T., Zhang, Y., and Allerton, J. (2018). Do growth mindsets in math benefit females? Identifying pathways between gender, mindset, and motivation. Journal of Youth and Adolescence, 47(5), 976-990.

Diekman, A. B., Weisgram, E. S., and Belanger, A. L. (2015). New routes to recruiting and retaining women in STEM: Policy implications of a communal goal congruity perspective. Social Issues and Policy Review, 9(1), 52-88.

Dweck, C. S. (2006). Mindset: The New Psychology of Success. New York: Ballantine Press.

Dweck, C. S., Walton, G. M., and Cohen, G. L. (2014). Academic tenacity: Mindsets and skills that promote long-term learning. Bill and Melinda Gates Foundation.

Eccles, J. S. (2007). Where are all the women? Gender differences in participation in physical science and engineering. In S. J. Ceci and W. M. Williams (Eds.), Why aren't more women in science? Top researchers debate the evidence (pp. 199-210). Washington, DC: American Psychological Association.
Erete, S., Pinkard, N., Martin, C. K., and Sandherr, J. (2016, August). Exploring the use of interactive narratives to engage inner-city girls in computational activities. In Research on Equity and Sustained Participation in Engineering, Computing, and Technology (RESPECT), 2016 (pp. 1-4). IEEE.

Gay, G. (2013). Teaching to and through cultural diversity. Curriculum Inquiry, 43(1), 48-70.

Gonsalves, A., Rahm, J., and Carvalho, A. (2013) "We could think of things that could be science": Girls' re-figuring of science in an out-of-school-time club. Journal of Research in Science Teaching, 50(9), 1068-1097.

Hazari, Z., Cass, C., and Beattie, C. (2015). Obscuring power structures in the physics classroom: Linking teacher positioning, student engagement, and physics identity development. Journal of Research in Science Teaching, 52(6), 735-762.

Hillman, S.J., Bloodsworth, K.H., Tilburg, C.E., Zeeman, S.I., and List, H.E. (2014). K-12 students' perceptions of scientists: Finding a valid measurement and exploring whether exposure to scientists makes an impact. International Journal of Science Education, 36(15), 2580-2595.

Hubert, T. L. (2014). Learners of mathematics: High school students' perspectives of culturally relevant mathematics pedagogy. Journal of African American Studies, 18(3), 324-336.

Hughes, R. (2015). An Investigation into the Longitudinal Identity Trajectories of Women in Science, Technology, Engineering, and Mathematics. Journal of Women and Minorities in Science and Engineering, 21(3), 181-213.

Hughes, R., and Molyneaux, K. (2014) Unpacking Secondary School Students' Identity Negotiations Regarding Science and Engineering: A Case Study in the United States. International Journal of Gender, Science, and Technology, 6(3), 291-309.

Hughes, R., Schellinger, J., and Roberts, K. (2020). The Role of Recognition in Disciplinary Identity for Girls. Journal of Research on Science Teaching. DOI:10.1002/tea.21665

Jethwani, M. M., Memon, N., Seo, W., and Richer, A. (2016). "I can actually be a super sleuth" Promising practices for engaging adolescent girls in cybersecurity education. Journal of Educational Computing Research, 55(1), 3-25.

Jones, T.C. (2019). Creating a world for me: Students of color navigating STEM identity. The Journal of Negro Education, 88(3), 358-378.

Kim, A.Y., Sinatra, G.M., and Seyranian, V. (2018). Developing a STEM Identity among Young Women: A Social Identity Perspective. Review of Educational Research, 88(4), 589625 .

Kim, H. (2016). Inquiry-based science and technology enrichment program for middle school-aged female students. Journal of Science Education and Technology, 25(2), 174-186. 
Koch, M., Lundh, P., and Harris, C. J. (2015). Investigating STEM support and persistence among urban teenage African American and Latina girls across settings. Urban Education, 54(2), 243-273.

Ladson-Billings, G. (2008). "Yes, but how do we do it?”: Practicing culturally relevant pedagogy. City kids, city schools: More reports from the front row, 162-177.

Ladson-Billings, G. (2014). Culturally relevant pedagogy 2.0: aka the remix. Harvard Educational Review 84(1) 74-84.

Levine, M., Serio, N., Radaram, B., Chaudhuri, S., and Talbert, W. (2015). Addressing the STEM gender gap by designing and implementing an educational outreach chemistry camp for middle school girls. Journal of Chemical Education, 92(10), 1639-1644.

Lock, R.M., and Hazari, Z. (2016). Discussing underrepresentation as a means to facilitating female students' physics identity development. Physical Review Physics Education Research, 12(2), 1-14.

Master, A., Cheryan, S., and Meltzoff, A. N. (2016). Computing whether she belongs: Stereotypes undermine girls' interest and sense of belonging in computer science. Journal of Educational Psychology, 108(3), 424.

McCreedy, D., and Dierking, L.D. (2013). Cascading influences: Long-term impacts of informal STEM experiences for girls. Philadelphia, PA: The Franklin Institute. Retrieved, January 2, 2014 from: https://www.fi.edu/sites/default/files/cascading-influences.pdf

National Research Council (NRC). (2009). Learning science in informal environments: People, places, and pursuits. Washington, DC: The National Academies Press.

National Science Foundation (2019). Women, minorities, and persons with disabilities in science and engineering. Retrieved from https://ncsesdata.nsf.gov/sere $/ 2018 / \mathrm{html} /$ sere 18 -dttab006.html.

NGSS Lead States. (2013). Next generation science standards: For states, by states. Washington, DC: National Academies Press.

O’Brien, L. T., Hitti, A., Shaffer, E., Van Camp, A. R., Henry, D., and Gilbert, P. N. (2016). Improving girls' sense of fit in science increasing the impact of role models. Social Psychological and Personality Science, 8(3), 301-309.

Philip, T.M., and Azevedo, F.S. (2017). Everyday science learning and equity: Mapping the contested terrain. Science Education, 101, 526-532. DOI: 10.1002/sce.21286

Polman, J.L., and Hope, J.M.G., (2014). Science news stories as boundary objects affecting engagement with science. Journal of Research in Science Teaching, 51(3), 315-341.

Richard, G.T. (2016). Chapter 5: At the intersections of play: Intersecting and diverging experiences across gender, identity, race, and sexuality in game culture. In Y.B. Kafai, G.T. Richard, and B.M. Tynes (Eds.), Diversifying Barbie and Mortal Kombat: Intersectional Perspectives and Inclusive Designs in Gaming (pp. 71-91). Pittsburgh, PA: Carnegie Mellon Press.
Riedinger, K., and Taylor, A. (2016). "I could see myself as a scientist": The potential of out-of-school time programs to influence girls' identities in science. Afterschool Matters, $23,1-7$.

Riegle-Crumb, C., and Morton, K. (2017). Gendered expectations: Examining how peers shape female students' intent to pursue STEM fields. Frontiers in Psychology, 8, 329-340. doi:10.3389/fpsyg.2017.00329

Robinson, A., Pérez-Quiñones, M. A., and Scales, G. (2016). African-American middle school girls: Influences on attitudes toward computer science. Computing in Science and Engineering, 18(3), 14-23.

Ryoo, J. J., and Kekelis, L. (2018). Reframing "failure" in making: The value of play, social relationships, and ownership. Journal of Youth Development, 12(4), 49-67.

Sammet, K., and Kekelis, L., (2016). Changing the Game for Girls in STEM: Findings on High Impact Programs and System-Building Strategies. Stemnext.org

Scott, K. A., and White, M. A. (2013). COMPUGIRLS' standpoint: Culturally responsive computing and its effect on girls of color. Urban Education, 48(5), 657-681.

Scott, K., Aist, G., and Zhang, X. (2014). Designing a culturally responsive computing curriculum for girls. International Journal of Gender, Science and Technology 6(2), 264-276.

Simpson, A., and Maltese, A. (2017). "Failure is a major component of learning anything": The role of failure in the development of STEM professionals. Journal of Science Educational Technology, 26, 223-237. DOI 10.1007/ s10956-016-9674-9.

Stewart-Gardiner, C., Carmichael, G., Latham, J., Lozano, N., and Greene, J. L. (2013). Influencing middle school girls to study computer science through educational computer games. Journal of Computing Sciences in Colleges, 28(6), 90-97.

Tan, E., Calabrese Barton, A., Kang, H., and O’Neill, T. (2013). Desiring a career in STEM-related fields: How middle school girls articulate and negotiate identities-in-practice in science. Journal of Research in Science Teaching, 50(10), 1143-1179.

Thomas, J. O., Rankin, Y., Minor, R., and Sun, L. (2017). Exploring the difficulties African-American middle school girls face enacting computational algorithmic thinking over three years while designing games for social change. Computer Supported Cooperative Work (CSCW), 26(4-6), 389-421.

Toh, P.L.L., and Kapur, M. (2017). Is having more prerequisite knowledge better for learning from productive failure? Instructional Science, 45, 377-394.

Warshauer, H.K. (2015). Productive struggle in middle school mathematics classrooms. Journal of Mathematics Teacher Education, 18, 375-400.

Weisgram, E. S., and Diekman, A. B. (2017). Making STEM "family friendly": The impact of perceiving science careers as family-compatible. Social Sciences, 6(2), 61. 